\title{
INCLUSÃO ESCOLAR SOB O VIÉS DO ENSINO COLABORATIVO: UMA EXPERIÊNCIA EM TRÊS INSTITUIÇÕES PÚBLICAS
}

\author{
VIANNA, Márcia Marin ${ }^{1}$ \\ MASCARO, Cristina Angélica Aquino de Carvalho² \\ MARETTI, Márcia Maria Baptista ${ }^{1}$ \\ BRAUN, Patrícia ${ }^{3}$
}

\begin{abstract}
RESUMO
Este texto descreve a experiência do ensino colaborativo como uma estratégia para efetivar processos de inclusão escolar em três escolas públicas localizadas no município do Rio de Janeiro, e reflete sobre a constituição de práticas e saberes em relação ao ensino de alunos com necessidades educacionais especiais. Os objetivos são: conceituar ensino colaborativo e descrever o processo de implantação desta estratégia nas unidades escolares e as ações decorrentes. O que caracteriza o ensino colaborativo como uma proposta inovadora não é só a cooperação entre os docentes, prevista em alternativas de trabalho como as salas de recursos, mas é a presença física de outro professor durante as atividades cotidianas. Além disso, no ambiente da sala de aula, o estudante tem a oportunidade de partilhar de diferentes pontos de vista apresentados por seus pares e, assim, se apropriar de ideias como não faria fora do ambiente de interação.
\end{abstract}

PaLAVRAS-CHAVE: Ensino colaborativo - Práticas pedagógicas - Inclusão escolar.

\section{ABSTRACT}

This paper describes the experience of collaborative learning as a strategy to actualize school inclusion process in three public schools located in the municipality of Rio de Janeiro, and reflects on the formation of practices and knowledge in relation to the teaching of students with special educational needs. The objectives are: conceptualize collaborative learning and describe the implementation process of this strategy at schools and actions arising. What characterizes collaborative learning as an innovative proposal is not only cooperation among teachers, scheduled for work alternatives as rooms resources but the physical presence of another teacher during everyday activities. In addition, the classroom environment, students

\footnotetext{
${ }^{1}$ Professora do Colégio Pedro II.

2 Professora da FAETEC e do Programa de Pós-graduação em Educação (ProPEd/UERJ).

${ }^{3}$ Professora Adjunta do Instituto de Aplicação Fernando Rodrigues da Silveira (CAp-UERJ) e do programa de Pósgraduação em Educação Básica (PPGEB).
} 
e-Mosaicos - Revista Multidisciplinar de Ensino, Pesquisa, Extensão e Cultura do Instituto de Aplicação Fernando Rodrigues da Silveira (CAp-UERJ)

V. 4 - N. 7 - JUNHO 2015 - ISSN: 2316-9303

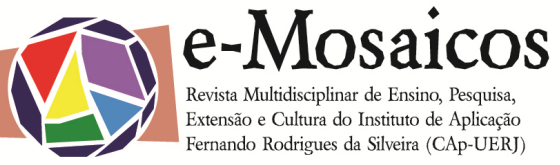

have the opportunity to share different points of view presented by their peers, and thus take ownership of ideas that would not out of the interaction environment.

KEY WORDS: Collaborative learning - Pedagogical practices - School inclusion.

\section{INTRODUÇÃO}

A diversidade humana, mais recentemente reconhecida e enfrentada no cotidiano escolar, tem revelado a urgência de ações pedagógicas que resultem em efetiva aprendizagem para todos, principalmente em relação aos desafios que se apresentam a partir da inclusão escolar de alunos com necessidades educacionais especiais em turmas comuns do ensino fundamental.

No cotidiano, tem sido cada vez mais recorrente a inserção de alunos com diferenças significativas em seus modos de aprender, por apresentarem deficiências (auditivas, visuais, físicas, motoras, mentais), altas habilidades, distúrbios de comportamento, transtornos psiquiátricos, dificuldades de aprendizagem, assim, como docentes de escolas públicas, impõe-se a nós uma busca por alternativas de trabalho pedagógico que efetivem as aprendizagens desses sujeitos que tiveram acesso ao ensino.

Nesse contexto, nossas práticas pedagógicas e estudos teóricos nos conduziram a investigar a proposta de ensino colaborativoem situações reais. Deste modo, apresentamos neste texto descritivo-analítico a constituição de práticas e saberes em relação ao ensino de alunos com necessidades educacionais especiais, integrantes de turmas comuns.

Trata-se de um relato que envolve o ensino colaborativo como uma estratégia para efetivar processos de inclusão escolar em três escolas públicas de redes diferenciadas, localizadas no município do Rio de Janeiro. São instituições que envolvem vários níveis de ensino: escolas de educação básica, que têm Ensino Fundamental e Médio; formação técnica; graduação e pós-graduação; são complexos educacionais. Uma escola é da rede federal, o Colégio Pedro II; as outras duas da rede estadual, vinculadas à Secretaria de Ciência e Tecnologia, o Instituto de Aplicação Fernando Rodrigues da Silveira (CAp-UERJ) e a Fundação de Apoio à Escola Técnica (FAETEC), voltada à Educação Profissional.

Fica esclarecido que a experiência descrita está circunscrita em turmas do Ensino Fundamental das três instituições, por onde se iniciaram as ações relacionadas ao ensino colaborativo.

Os objetivos do relato são: conceituar ensino colaborativo; descrever - processo de implantação desta estratégia nas unidades escolares e as ações dela decorrentes.

\section{ENSINO COLABORATIVO COMO CONCEITO}

Cabe explorar, inicialmente, as teorias que sustentam este relato, são concepções que afetam a dinâmica escolar e promovem a reflexão a partir da prática. Os primeiros estudos que nos possibilitaram contato com a ideia de ensino colaborativo foram de Beyer (2005; 2010), que denominava, em seus textos, de "sistema da bidocência". Com base em experiências de escolas alemãs, há a descrição sobre a ação de professores especialistas atuando em colaboração com os professores de turmas comuns, como uma alternativa aos processos de inclusão. Deste modo, indicamos, junto com o 
e-Mosaicos - Revista Multidisciplinar de Ensino, Pesquisa, Extensão e Cultura do Instituto de Aplicação Fernando Rodrigues da Silveira (CAp-UERJ)

autor, que ensino colaborativo pressupõe o seguinte:

Toda a classe inclusiva dispõe do suporte de um segundo professor, em regra com formação especializada. Com isto, torna-se realizável uma orientação individual conforme as possibilidades e necessidades de cada criança, particularmente o aluno com necessidades especiais (BEYER, 2005, p.6).

Buscando produções sobre o tema, nos deparamos com definições e explicações de outros investigadores:

A literatura estrangeira vem apontando que a colaboração entre professores da Educação Comum e Especial tem possibilitado uma reflexão da prática pedagógica e ampliando as possibilidades de melhor atender alunos com deficiência na classe comum, além de possibilitar um desenvolvimento profissional centrado na própria escola (CAPELLINI; MENDES, 2007, p.119).

Somente a inserção, como presença física, como mais uma matrícula, de estudantes com deficiências ou outras necessidades especiais numa turma comum, não garante participação e aprendizagens escolares. O conhecimento dos profissionais da área de educação especial faz diferença na hora de planejar como ensinar alunos que aprendem por percursos diferentes. Deste modo, a presença de um segundo professor em sala, durante a aula, como apoio no processo de ensino, caracteriza a estratégia de ensino colaborativo. Essa alternativa se apresenta na contramão de processos segregativos. Para além de um acompanhamento em sala, no decorrer da aula, a proposta envolve o planejamento conjunto:

Um modelo muito promissor é o de ensino colaborativo, que consiste em uma parceria entre os professores de Educação Regular e os professores de Educação Especial, na qual um educador comum e um educador especial dividem a responsabilidade de planejar, instruir e avaliar os procedimentos de ensino a um grupo heterogêneo de estudantes (FERREIRA; MENDES; ALMEIDA; DEL PRETTE; 2007,s/p.).

Esse aspecto da divisão de responsabilidade em relação ao planejamento e ao manejo da turma, como um todo, é um ideal a ser alcançado, pois a implantação do trabalho envolve novas relações profissionais, outras dinâmicas em sala de aula, diferentes modos de intervenção pedagógica, a serem constituídos no fazer cotidiano, pela ação e reflexão.

Ainda encontramos outras discussões sobre essa estratégia como alternativa aos modelos vigentes, o trecho abaixo esclarece e sintetiza isso:

O ensino colaborativo ou coensino é um modelo de prestação de serviço de educação especial no qual um educador comum e um educador especial dividem a responsabilidade de planejar, instruir e avaliar a instrução de um grupo heterogêneo de estudantes. Ele emergiu como uma alternativa aos modelos de sala de recursos, classes especiais ou escolas especiais, como um modo de apoiar a escolarização de estudantes com necessidades educacionais especiais em classes comuns. Assim, a invés dos alunos com necessidades educacionais especiais irem para classes especiais ou de recursos, é o professor especializado que 
vai até a classe comum na qual o aluno está inserido colaborar com - professor do ensino regular (MENDES; ALMEIDA; TOYODA; 2011, p. 85).

Essa parceria entre os docentes pode ser uma alternativa "menos artificial" de promover inclusão, pois quando pessoas com necessidades educacionais específicas estão numa turma comum e suas diferenças não são consideradas, terão, na verdade, suas desvantagens evidenciadas. É preciso garantir apoios e diferenciações para que possam aprender, e fazer diferente para garantir a igualdade.

Deste modo, a estratégia foi sendo compreendida e assimilada como uma possibilidade prática, que pode ser executada em nossos espaços de trabalho. O desafio de ter alunos nas turmas comuns e vê-los avançando nos anos escolares indica maiores exigências em relação aos processos de ensino, em razão da complexidade e volume dos conteúdos. Ter alunos com comprometimentos mais acentuados, em uma turma, impulsiona a busca por estratégias que garantam a inclusão escolar com 0 tripé que a sustenta: acesso, permanência e aprendizagem.

No Brasil não há uma previsão legal clara sobre o ensino colaborativo como uma estratégia. Porém, de nossa perspectiva, é possível compreender a sua viabilização na Resolução n. 02/01 que institui as Diretrizes Nacionais para a Educação Especial na Educação Básica, em seu Art. $8^{\circ}$, quando diz que:

As escolas da rede regular de ensino devem prever e prover na organização de suas classes comuns: IV serviços de apoio pedagógico especializado, realizado, nas classes comuns, mediante: a) atuação colaborativade professor especializado em educação especial; b) atuação de professores-intérpretes das linguagens e códigos aplicáveis; c) atuação de professores e outros profissionais itinerantes intra e interinstitucionalmente; d) disponibilização de outros apoios necessários à aprendizagem, à locomoção e à comunicação (BRASIL, 2001a, grifo nosso).

O Parecer n.17/01, sobre as mesmas diretrizes, destaca que "o corpo docente, e não cada professor, deverá partilhar a responsabilidade do ensino ministrado a crianças com necessidades especiais" (BRASIL, 2001b, p. 7). Entendemos que isso dá respaldo legal à perspectiva do ensino colaborativo.

No entanto, para a efetivação dessa perspectiva, faltam recursos humanos para sua viabilização, no que se refere à disponibilização de mais professores, pois há entraves econômicos, administrativos e burocráticos que ainda limitam a implantação e expansão dessa ação.

Mesmo com esses entraves, entendemos que a proposta de colaboração entre docentes, especialistas e do ensino comum, pode se traduzir em uma resposta eficaz para favorecer uma prática pedagógica que atenda a diversidade. A questão emergencial posta é organizar este trabalho no cotidiano escolar.

O propósito é garantir a articulação de saberes entre ensino especial e comum, combinando as habilidades dos dois professores. Assim, o professor regente da turma traz os saberes disciplinares, os conteúdos, o que prevê o currículo e o planejamento da escola, juntamente com os limites que enfrenta para ensinar o aluno com necessidade especial. 0 professor do ensino especial, por 
sua vez, contribui com propostas de adequação curricular, atentando para as possibilidades do estudante, considerando as situações de ensino propostas e as opções metodológicas, planejando estratégias e elaborando recursos adequados para a promoção de sua aprendizagem (MARIN; BRAUN, 2013, p. 53).

\section{ENSINO COLABORATIVO COMO PRÁTICA}

A intenção aqui é descrever experiências desenvolvidas nas instituições em que temos vínculo de atuação profissional. Constatamos que as ações de implantação seguiram um percurso semelhante, que serão descritos a seguir.

No Colégio Pedro II, na então Unidade Engenho Novo I, atualmente campus, o trabalho teve início entre os anos de 2007 e 2008, no Fundamental I, sendo que a experiência chamou-se inicialmente de bidocência. O acompanhamento organizou-se em forma de itinerância, não foi exclusivo para uma turma, pois se constituiu para apoiar um aluno surdo, que não fazia uso de LIBRAS, e, em outra turma, um aluno com Transtorno do Espectro do Autismo (TEA). Ambos acabavam de chegar na escola por sorteio público, que é o meio de acesso aos anos iniciais, e apresentavam demandas específicas, que a escola constatou que não teria como resolver sem uma mediação nasaulas.

O profissional designado para a função foi uma professora efetiva, com formação em educação especial, que anteriormente estava ligada a um trabalho também de apoio específico para alunos com dificuldades de aprendizagem, chamado Laboratório de Aprendizagem (LA).
Depois, essa professora assumiu a função docente no Atendimento Educacional Especializado(AEE), em 2009, e deu continuidade à ação no ensino colaborativo, além de atender na sala de recursos multifuncional (SRM). A partir de 2011, com a inserção dos alunos do Fundamental I para o II, passam a ser duas professoras de SRM, acompanhando alunos durante a aula. Atualmente, são cinco estudantes, dois com TEA e os outros com deficiência intelectual, dois do Fundamental I.

Para o desenvolvimento inicial da proposta, desafios se colocavam para a mediação em sala de aula: conquistar a confiança dos professores das disciplinas; diminuir o estranhamento causado pela presença de um segundo professor no cotidiano; elaborar o plano de ensino individualizado, acompanhando o planejamento da turma; propor alterações nos encaminhamentos das aulas e nos objetos de avaliação; construir uma imagem positiva de inclusão uma vez que, em sua grande maioria, a presença de alunos com necessidades específicas é marcada por insucessos causados pela ausência de parcerias; participar dos Conselhos de Classe e das reuniões de planejamento semanais das disciplinas, colaborando com materiais e sugestões de estratégias; oferecer material informativo para os docentes.

Há avaliações positivas, tanto por parte da gestão escolar, quanto das famílias e dos próprios docentes, no que se refere à estratégia aplicada.

No Instituto de Aplicação Fernando Rodrigues da Silveira (CAp/UERJ), a origem dessa estratégia, que está em implantação desde 2011, foi um projeto de Iniciação à Docência $^{4}$ 2, Necessidades

\footnotetext{
${ }^{4}$ Os projetos de iniciação à docência envolvem instituições de ensino superior e escolas básicas,
} 
Especiais em Processos de Inclusão, em andamento desde 2006.

A ação, em linhas gerais, ocorre do seguinte modo: inicialmente, cada aluno que apresenta uma necessidade educacional especial, é observado pelos professores da turma e pelo professor de educação especial. A partir da indicação da possível necessidade de acompanhamento, os docentes, em conjunto com a equipe pedagógica da escola, verificam a necessidade e o caráter do atendimento educacional especializado na forma do ensino colaborativo. Estabelece-se um plano de horário para o acompanhamento específico e contatos com a família ocorrem para compartilhar e encaminhar a proposta.

No desenvolvimento da estratégiana rotina escolar, foram sendo organizados documentos e orientações paramelhor elaboração de um planejamento conjunto, assim otrabalho segue com avaliações ${ }^{5}$ durante 0 processo.

Lidar com a perspectiva de inclusão escolargera uma série de questionamentos entre os profissionais. A transcrição do relato abaixo, escrito por uma professora como partedas avaliações relacionadasao trabalho, aponta o ensino colaborativo como possibilidade para efetivação de práticas de inclusão escolar.

Atualmente, tenho muitas questões quanto à inclusão

contam com agências de fomento que disponibilizam bolsas para promover a inserção de estudantes de licenciaturas no contexto das escolas públicas desde o início da sua formação acadêmica para que desenvolvam atividades didáticopedagógicas sob orientação de um docente da licenciatura e de um professor da escola.

5 São documentos oficiais para a proposta: uma ficha individualizada de acompanhamento escolar trimestral com critérios de desempenho por área de conhecimento e um relatório descritivo semestral. educacional. Penso que deveria ser de forma diferente, não basta matricular a criança numa turma e apenas "incluí-la" na lista. Precisamos de pessoas com formação específica para acompanhar essa criança, em alguns momentos na sala de aula, discutir as questões que surgem com o professor da turma e em outros momentos, fora da sala de aula, para realizar atividades específicas. Não basta fazer a inclusão numa turma, sem oferecer estratégias mais direcionadas às necessidades da criança (Professora do $1^{\circ}$ ano do Ensino Fundamental, agosto de 2010).

A FAETEC é uma instituição voltada para a Educação Profissional em todos os níveis e modalidades de ensino e busca, desde 2003, encontrar formas de se tornar um espaço escolar inclusivo, garantindo, além do acesso, a permanência dos alunos com necessidades educacionais especiais em seus cursos. Além de Faculdades Tecnológicas e Institutos Superiores de Educação, Escolas Técnicas de Nível Médio, Cursos de Formação Inicial e Continuada, possui escolas de Ensino Fundamental e uma escola especial para alunos com deficiência intelectual.

Esse movimento da política de inclusão traduziu-se em um entrave no que se refere à ressignificação da escola especial da FAETEC, visto que a mesma possuía mais de duzentos alunos, com idade variando de 7 a 40 anos, matriculados exclusivamente na Educação Especial.Sendo assim, estabeleceu-se, por parte da instituição, uma parceria com a Universidade do Estado do Rio de Janeiro, com objetivo de encontrar possibilidades de ressignificar esta escola especial da rede. Em 2009, em parceria com o Programa de Pós-Graduação da UERJ, por meio do grupo de pesquisa e o setor da 
FAETEC denominado Divisão de Inclusão ${ }^{6}$, iniciou-se um projeto voltado para pensar os caminhos desta escola especial. Para os alunos que se encontravam fora da idade escolar, foi elaborada uma proposta de cursos de formação profissional adaptados, para os alunos que ainda não poderiam se incluir nos cursos regulares da rede.

O recorte aqui é em relação à proposta para os alunos com idade entre 7 e 14 anos, havia que se pensar uma proposta para eles. Nesse sentido, foi elaborada uma pesquisa na escola especial objetivando a investigação de uma estratégia denominada Plano Educacional Individualizado

(MARIN; MASCARO;SIQUEIRA, 2013), no sentido de ressignificar as ações pedagógicas desenvolvidas neste espaço especializado de educação. Havia também um trabalho de conscientização realizado pela equipe pedagógica da escola com as famílias,no sentido de incentivar que os filhos fossem matriculados na escola de Ensino Fundamental comum. Ambas as escolas se localizam no campus Quintino, ficando uma ao lado da outra.

Apesar do trabalho, as matrículas no ensino comum, até o ano de 2012 não haviam acontecido. Sendo assim, a Divisão de Inclusão apresentou, ao final deste ano, a proposta de um projeto denominado Bidocência, que consistia em matricular os alunos mais novos da escola especial, na escola de Ensino Fundamental da própria instituição, que fica no mesmo campus, garantindo a contratação de um professor de Educação Especial para atuar nas turmas em que estivessem matriculados alunos com deficiência intelectual.

O projeto foi apresentado às famílias, cerca de doze responsáveis de

\footnotetext{
${ }^{6}$ Composto por professores de Educação Especial
}

alunos da escola especial, e quatro concordaram em matricular seus filhos. Em 2013, então, iniciou-se o Projeto Bidocência com duas turmas, recebendo, cada uma, dois alunos com deficiência intelectual. Uma turma em cada turno, cada uma com um professor do ensino comum e um professor de Educação Especial com a proposta de compartilhar o ambiente da sala de aula. Ao longo do ano de 2013, dois alunos (um de cada turma) solicitaram transferência.

Nos encontros de acompanhamento do projeto, ocorridos entre a escola de ensino fundamental e os professores especialistas da Divisão de Inclusão, ficou evidenciado, nos relatos da supervisão da escola, que a chegada de alunos com deficiência intelectual na escola foi positiva para a equipe e demais alunos. Em sua avaliação, a supervisora pedagógica aponta que, até então, havia a concepção de que o lugar "daqueles alunos" era na escola especial, porém, com a convivência, muitos mitos foram superados. Destacamos o fato de que uma das alunas participantes da experiência apresentava rendimento acadêmico em leitura melhor que dos alunos considerados da turma em geral.

Durante 0 desenvolvimento da proposta, foram constatados alguns impasses como, por exemplo, o estabelecimento de uma real parceria entre os docentes do ensino comum e especial no cotidiano. O trabalho com ensino colaborativo requer a construção gradativa desta parceria pedagógica para ensinar. Em alguns relatos dos docentes especialistas, os mesmos diziam serem percebidos ou como mediador do aluno com deficiência intelectual ou um assistente de turma. Tais questões são trabalhadas com todos ao longo de reuniões. A intenção é construir gradativamente a proposta da docência compartilhada. 
e-Mosaicos - Revista Multidisciplinar de Ensino, Pesquisa, Extensão e Cultura do Instituto de Aplicação Fernando Rodrigues da Silveira (CAp-UERJ)

No decorrer de um ano letivo da pesquisa, foi feita a avaliação das alunas com deficiência intelectual com objetivo de traçar as metas para o próximo ano. A aluna do turno da manhã apresentou dificuldades para acompanhar a turma, não conseguindo se alfabetizar. Sendo assim,a decisão da escola foi aprová-la para o segundo ano, mantendo a bidocência e inserindo-a também no atendimento em sala de recursos com objetivo de ter maior suporte para seu desenvolvimento acadêmico. A do turno da tarde acompanhou bem a proposta do primeiro ano e se alfabetizou, no mesmo nível que a turma, apresentando dificuldades com a matemática. A proposta para ela foi de aprovação para o segundo ano, porém com apenas três dias semanais de bidocência e atendimento na sala de recursos no contra turno.

Ao final do ano de 2013, o trabalho desenvolvido na escola de ensino fundamental foi apresentado aos pais da escola especial, e em 2014 foram matriculados mais quatro alunos oriundos da escola especial.

Ressaltamos que os relatos de cada instituição foram descritos em linhas gerais. Nas conclusões serão abordados os pontos comuns dessa experiência.

\section{CONCLUSÕES}

A força da colaboração encontrase na capacidade de unir as habilidades individuais dos educadores, para promover sentimentos de interdependência positiva, desenvolver habilidades criativas de resolução de problemas e apoiar um ao outro, de forma que todos assumam as responsabilidades educacionais (CAPELLINI; MENDES, 2007, p.126).
Conseguimos constatar que há pontos comuns entre as experiências desenvolvidas nas três instituições, CAp/UERJ, Colégio Pedro II e FAETEC.

Um deles é a confirmação de que a maior demanda para o estabelecimento da estratégia do ensino colaborativo relaciona-se aos casos de alunos com deficiência intelectual e quadros do espectro autista, pois requerem maior intervenção imediata nas ações ocorridas durante a aula, necessitam de interlocução constante e os professores apontam prioridades para o apoio no de correrdas atividades escolares.

A inserção em sala de aula, em termos da utilização do tempo, tem funcionado como uma itinerância, pois não há mão de obra suficiente para se fazer a parceria de um a um, ou seja, um professor por aluno, em tempo integral de aula; deste modo, consideram-se as demandas do aluno e organiza-se um horário. Há alunos que são acompanhados durante todas as aulas, em todos os dias, outros não. O critério de frequência está relacionado à autonomia apresentada pelo aluno em tarefas escolares e participação em aula,e às necessidades que o docente apresenta para desenvolver os processos de ensino.

Há ações que se caracterizam por momentos de individualização, quando é mais adequado retirar o aluno de sala, durante o horário da aula, para favorecer processos de ensino e aprendizagem, com o uso de recursos específicos, como materiais concretos ou adaptados, variação de linguagem. Pode ser a mesma atividade que está sendo desenvolvida com a turma, mas com recursos e procedimentos diferentes, ou poderá ser outra atividade relacionada ao que o aluno precisa aprender naquele momento.

A participação do docente especializado, na perspectiva do ensino 
e-Mosaicos - Revista Multidisciplinar de Ensino, Pesquisa, Extensão e Cultura do Instituto de Aplicação Fernando Rodrigues da Silveira (CAp-UERJ)

colaborativo, em sala de aula é sempre em atenção à criança em processo de inclusão. Porém, a circulação em sala e o apoio a outros alunos acontecem, como uma forma de melhor interação com todos, na busca de parceiros para promover a tutoria em pares entre colegas, para minimizar a ideia de exclusividade para determinado aluno, que pode resultar em discriminação, essa é a melhor configuração que vislumbramos do que seja essa prática.

Sendo assim, os docentes que atuam colaborativamente em sala precisam de liberdade e autonomia para reger o processo de ensino, estabelecendo regras quanto aos seus papéis de referência e de autoridade, seja com a turma ou com um aluno, há necessidade de que reconheçam que se encontram numa área de negociação constante, onde a cumplicidade no ato pedagógico é a base do trabalho. Para Mendes, Vilaronga e Zerbato (2014), o coensino, docência compartilhada 0 ensino colaborativo requer um voluntarismo por parte dos docentes para que o trabalho aconteça. Porém, mesmo constatando que existência de professores indisponíveis para uma parceria, isso não pode ser considerado um impedimento para a realização da proposta. Para as autoras, essa resistência inicial acontece pelo fato de ser recente a cultura da colaboração entre docentes do ensino especial e comum, este modelo de trabalho deve ser negociado e construído no cotidiano das escolas.

A formação de saberes docentes e práticas de inclusão inserem-se na constituição de uma nova cultura escolar, que precisamente deve ter como meta a construção de procedimentos de ensino com objetivos, recursos e estratégias diversificadas, de modo a favorecer 0 processo de construção de conhecimentos (BRAUN; MARIN, 2012, p.4).
Fica evidente a formação de novas identidades: de estudantes que em outros contextos estariam fadados ao fracasso e à exclusão escolar e de seus pares na vivência com a diferença; de docentes para a diversidade, que estão em busca de novas estratégias para suas ações pedagógicas, sejam especialistas ou não; de graduandos em formação inicial, que nas situações de estágio vão se formando para uma escola que envolve processos de inclusão; das famílias que passam a compreender novas relações escolares; e da cultura escolar no dinamismo de diversos tempos e espaços, com outras formas para ensinar, aprender e conviver.

Outro desafio enfrentado pelas três unidades escolares se relaciona à organização administrativa para alocar os docentes na função do ensino colaborativo, a análise de Beyer (2005, p.6) já apontava para essa realidade da falta de mão de obra:

Devido ao fato de que, em geral, as limitações quanto aos docentes disponíveis para as escolas públicas sejam relativamente severas nas redes de ensino nos municípios e estados brasileiros, não se pode sonhar com um sistema de bidocência nas classes de inclusão escolar. Porém, podese pensar na disponibilidade dos professores das salas de recursos, já existentes nas redes de ensino. Em vez dos mesmos concentrarem sua prática docente nas salas de recursos, poderiam destinar parte das suas horas-aula para acompanhar 0 professor regente na própria sala de aula e interagir diretamente com o grupo de alunos. 
Cada instituição, na experiência relatada, precisou buscar saídas para ter professores atuando como outro docente em salas de aula. No Colégio Pedro II, duas professoras de Sala de Recursos fazem a função do ensino colaborativo, coordenando essa atuação com o trabalho no contra turno, com grupos no Atendimento Educacional Especializado (AEE). A FAETEC, pelo Projeto de Bidocência, contratou professores para função. $E$ o CAp-UERJ, num longo processo de negociação, oficializou a função do professor de Ensino Colaborativo.

Concluímos que o que caracteriza o ensino colaborativo como uma proposta inovadora não é só a cooperação entre os docentes, prevista em alternativas de trabalho como as salas de recursos, mas é a presença física de outro professor durante as atividades cotidianas, por isso compreendemos que a estratégia pode também ser denominada de coensino ou bidocência (BEYER, 2005; 2010; FONTES, 2009). Além disso, é importante ressaltar que, no ambiente da sala de aula, o estudante tem a oportunidade de partilhar de diferentes pontos de vista apresentados no seu linguajar, por seus pares, e assim se apropriar de ideias e conceitos, algo que não faria fora do ambiente de interação.

\section{REFERÊNCIAS BIBLIOGRÁFICAS}

BEYER, Hugo Otto. Pioneirismo da escola (modelo) Flämming na proposta de integração (inclusão) escolar na Alemanha: aspectos pedagógicos decorrentes. Revista Educação Especial. Universidade de Santa Maria/ Cascavel. $\mathrm{n}$. 25, 2005, p. 9 - 24. Disponível em: <http://cascavel.ufsm.br/revistas/ojs2.2.2/ index.php/educacaoespecial/issue/view/24 5/showToc $>$.Acesso em 08 de maio de
2014.

. Inclusão e avaliação na escola de alunos com necessidades educacionais especiais. Porto Alegre: Mediação, 2010.

BRASIL. Resolução CNE/CEB N.2/2001, Institui Diretrizes Nacionais para a Educação Especial na Educação Básica, de 11 de setembro de 2001a. Disponível em: $<$ http://portal.mec.gov.br/cne/arquivos/pd f/CEB0201.pdf >. Acesso em 10 de maio 2014.

BRASIL. Parecer CNE/CBE 17/2001, Diretrizes Nacionais para a Educação Especial na Educação Básica, Diário Oficial da União de 17/8/2001, Seção 1, p. 46. 2001b. Disponível em: <http://portal.mec.gov.br/seesp/arquivos/ pdf/parecer17.pdf $>$. Acesso em 10 de maio de 2014.

BRAUN, Patrícia; MARIN, Márcia. Práticas docentes em tempos de inclusão: uma experiência na escola básica. e-Mosaicos, Revista Multidisciplinar de Ensino, Pesquisa, Extensão e Cultura do Instituto de Aplicação Fernando Rodrigues da Silveira (CAp-UERJ), ano 1, vol.1, n. 2, dez/ 2012, p. 1-12. Disponível em: $<$ http://www.e-

publicacoes.uerj.br/index.php/emosaicos/article/view/5152/3776>. Acesso em: 15 de junho de 2014.

CAPELLINI, Vera Lúcia Messias Fialho; MENDES, Enicéia Gonçalves. O ensino colaborativo favorecendo 0 desenvolvimento profissional para a inclusão escolar. Educereeteducare Revista de Educação. UNIOESTE/Campus Cascavel. v. 2. n.4 jul/dez, 2007, p. 113128.

FERREIRA, Bárbara Carvalho; MENDES, Enicéia Gonçalves; ALMEIDA, Maria Amélia; DEL PRETTE, Zilda Aparecida 
Pereira. Parceria colaborativa: descrição de uma experiência entre o ensino regular e especial. Revista do Centro de Educação/Cadernos, UFSM, n. 29, Edição 2007, s.p. Disponível em: <http://coralx.ufsm.br/revce/ceesp/2007/ 01/a1.htm>. Acesso em maio de 2014.

FONTES, Rejane de Souza. Ensino colaborativo: uma proposta de educação inclusiva. Araraquara, SP: Junqueira \& Marin, 2009.

MARIN, Márcia; BRAUN, Patrícia. Ensino colaborativo como prática de inclusão escolar. In: GLAT, Rosana; PLETSCH, Márcia Denise (org.). Estratégias educacionais diferenciadas para alunos com necessidades especiais. Rio de Janeiro: EdUERJ, 2013,p. 49-64.

MARIN, Márcia; MASCARO, Cristina Angélica Aquino de Carvalho; SIQUEIRA, Carla Fernanda. Plano educacional individualizado (PEI): um estudo sobre sua utilização numa escola especial. In: GLAT, Rosana; PLETSCH, Márcia Denise (org.). Estratégias educacionais diferenciadas para alunos com necessidades especiais. Rio de Janeiro: EdUERJ, 2013, p. 91- 105.

MENDES, Enicéia Gonçalves; ALMEIDA, Maria Amélia; TOYODA, Cristina Yoshie. Inclusão escolar pela via da colaboração entre educação especial e educação regular. Educar em Revista, Curitiba, Brasil, n. 41, p. 81-93, jul./set. 2011. Editora UFPR. Disponível em:<http://www.redalyc.org/src/inicio/Art PdfRed.jsp?iCve $=155021076006>$. Acesso em 10 de julho de 2014.

MENDES, Enicéia Gonçalves; VILARONGA, Carla Ariela Rios; ZERBATO, Ana Paula. Ensino Colaborativo: unindo esforços entre Aceito em: 30/06/2015 educação comum e especial. São Carlos: EdUFSCar, 2014. 